\title{
An active exercise and posture protocol reduced pain in acute whiplash injuries
}

\author{
Rosenfeld M, Gunnarsson R, Borenstein P. Early intervention in whiplash-associated disorders. A comparison of two \\ treatment protocols. Spine 2000 Jul 15;25:1782-7.

\section{QUESTIONS: In patients with acute whiplash injuries, is an active treatment protocol more effective than standard treatment for reducing pain? Is early initiation better than delayed initiation of treatment?}

Design

Randomised \{allocation concealed*\}†, unblinded, controlled trial with 6 months of follow up.

\section{Setting}

29 primary care units, 3 emergency wards, and several private clinics in Elfsborg County, southwestern Sweden.

\section{Patients}

102 patients who had an acute whiplash injury and could be randomised within 96 hours after the traumatic event. Exclusion criteria were cervical fractures, cervical dislocation, head injury, previously known symptomatic chronic neck problems, alcohol abuse, dementia, serious mental illness, or terminal illness. Follow up was $86 \%$ of randomised patients (mean age 36 y, $67 \%$ women).

\section{Intervention}

Patients were allocated to 1 of 4 groups: to active treatment within 96 hours $(\mathrm{n}=21)$ or after 2 weeks $(n=22)$ or to standard treatment within 96 hours $(n=23)$ or after 2 weeks $(n=22)$. Active treatment consisted of gentle, active, small range and small amplitude rotational movements of the neck, which were repeated 10 times in each direction every hour when awake. The protocol included additional dynamic mechanical evaluation and an individual treatment programme based on repeated movements when symptoms persisted for $>20$ days. Standard treatment consisted of a leaflet providing information about injury mechanisms, advice on suitable activities, and instructions on postural correction.

\section{Main outcome measures}

Change in range of motion (ROM) and pain (assessed by using a $100-\mathrm{mm}$ visual analogue scale [VAS])

\section{Main results}

Fewer patients had pain after active treatment than after standard treatment $\{\mathrm{p}=0.03\} \$$ (table). Active treatment within 96 hours led to reduced pain (mean VAS decrease $30 \mathrm{~mm}$ ), whereas standard treatment led to an increase in pain (mean VAS increase $0.74 \mathrm{~mm}$ ). Active and standard treatment within 2 weeks led to mean reductions of 15 $\mathrm{mm}$ and $7.1 \mathrm{~mm}$, respectively, on the pain VAS. More patients in the active treatment group than in the standard treatment group had no or low pain $(\leqslant 10 \mathrm{~mm}$ on the VAS) at follow up $\{p=0.01\} \ddagger$ (table). Active and

Active v standard treatment for whiplash injury at 6 months

\begin{tabular}{lllll} 
Outcomes & $\begin{array}{l}\text { Active } \\
\text { treatment }\end{array}$ & $\begin{array}{l}\text { Standard } \\
\text { treatment }\end{array}$ & RBI (95\% Cl) & NNT (CI) \\
No pain & $30 \%$ & $11 \%$ & $172 \%(12$ to 588$)$ & 6 (3 to 45$)$ \\
\hline No or low pain & $44 \%$ & $20 \%$ & $121 \%(16$ to 336$)$ & 5 (3 to 22) \\
\hline §Abbreviations defined in glossary; RBI, NNT, and Cl calculated from data in article.
\end{tabular}

standard treatment did not differ for improvement in cervical ROM. Analysis of interactions between group and time showed that results were better when active treatment was initiated earlier rather than later.

\section{Conclusions}

In patients with whiplash injuries caused by motor vehicle collision, an active exercise and posture protocol reduced pain. Early initiation (within 96 hours) was better than late initiation (after 2 weeks) of active treatment.

*See glossary.

$\dagger$ Information provided by author.

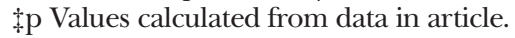

\section{COMMENTARY}

The study by Rosenfeld $e t$ al adds to the growing literature on the rational treatment of acute soft tissue injury. "Early mobilization as tolerated" is effective for both whiplash injury and acute low back pain. ${ }^{12}$ In this study, such "active management" is reflected in the use of the McKenzie method.

A major goal of the treatment of acute whiplash injury is prevention of the chronic whiplash syndrome. Whether the chronic condition is functional (chronic illness behaviour) or organic (persistent tissue injury) is a matter of some debate. ${ }^{3}$

It is recognised that chronic illness behaviour may be engendered if a minor injury is overdiagnosed, overtreated, and overcompensated. ${ }^{4}$ Fear and anxiety about the outcome and scrutiny by the medicolegal system may cause the patient to expect pain, amplify it, and attribute the pain to the original event. ${ }^{4}$ This study's treatment protocol acts to allay fears of a serious injury and permits the patient to immediately exercise the injured part within comfort limits. Continued supervision also provides ongoing reassurance of a satisfactory outcome. Thus, the treatment may act primarily as a means to promote wellness behaviour.

Those who favour the organic cause of chronic whiplash injury would emphasise that early mobilisation may avoid the "disuse syndrome" that often leads to soft tissue atrophy, decreased regional blood flow, and decreased healing. Regardless of its mechanism, an active exercise and postural protocol reduces pain in the acute whiplash injury and may decrease progression to the chronic whiplash syndrome.

Robert A Hawkins, MD Wright State University Centreville, Ohio, USA

1 Vendrig AA, van Akkerveeken PF, McWhorter KR. Results of a multimodal treatment program for patients with chronic symptoms after a whiplash injury of the neck. Spine 2000;25: $238-44$.

2 Deyo RA, Diehl AK, Rosenthal M. How many days of bed rest for acute low back pain? A randomized clinical trial. $N$ Engl J Med 1986:315:1064-70.

3 Hachinski V. Whiplash. Arch Neurol 2000;57:594.

4 Ferrari R, Russell AS. Epidemiology of whiplash: an international dilemma. Ann Rheum Dis 1999;58:1-5. 